\title{
ВАЛЕНТИНА ГОЛОВЧИНЕР
}

Томский государственный педагогический университет

Кафедра литературы и методики ее преподавания

634061 Томск

ул. Киевская, 60

golovchiner@mail.ru

\section{«ЖИТИЕ» И «БЫТИЕ» В ПЬЕСАХ-ПРИТЧАХ АЛЕКСАНДРА ЧИРКОВА}

\section{'LIVING' AND 'BEING' IN THE DRAMATIC PARABLES OF ALEKSANDR CHIRKOV}

Статья посвящена редкому для современной русскоязычной драмы явлению - пьесампритчам. Их автор - А. Чирков живет на Украине, где особенно остро проявляется трагизм современного бытия. Его драматургия выражает напряженные размышления о природе власти, о связях между теми, кто, направляет к своей выгоде потоки исторических событий, и теми, кто, не задумываясь о последствиях, исполняет чужую волю. Выявляется обобщающая поэтика этих пьес, позволяющая видеть в них авторские модели условно-метафорического направления эпической драмы.

Ключевые слова: Александр Чирков, актуальная проблематика, поэтика эпической драмы, притча.

The paper is devoted to a phenomenon rare for the modern Russian-language drama: playsparables by the Ukrainian playwright Aleksandr Chirkov. They represent the author's reflection on the reasons of the contemporary tragedy of existence, and a study of the connections between those who govern historical events for their own benefit and those who follow the will of others without thinking of consequences. Artistic generalization is revealed, which allows one to see in them the author's models of conventional-metaphoric type of epic drama.

Keywords: Aleksandr Chirkov, topical issues, poetics of epic drama, parable.

Так случилось, что впервые имя Александра Семеновича Чиркова я увидела на его монографии Эпическая драма (проблемы теории и поэтики). 
Она была представлена на выставке новых поступлений в Научной библиотеке далекого от Киева Томского государственного университета ${ }^{1}$. Через издательство я узнала адрес украинского коллеги, и завязалась переписка - сначала редкая, но постепенно количество поводов для переписки увеличивалось.

В последние три - четыре года материалом обсуждения стали, в том числе, и собственные художественные произведения А. Чиркова. В эту сложную для него лично, для нас и для наших народов пору - прежде всего, противостояния Украины и России в нем проснулся, видимо, всегда дремавший дар поэта и драматурга. Я получила книжечку притч, потом пошли пьесы... Как будто что-то копилось в человеке, бродило, зрело и, наконец, нашло выход. Он не мог их не писать. Они пробивались, просто шли через него. Думается, литературное творчество стало его спасательным кругом в бушующем море событий, угрожающем жизни ближних и дальних.

Ситуация сложилась весьма своеобразная. Пьесы немолодого человека $^{2}$ и молодого драматурга могут кому-то показаться странными на фоне потока «новой», «новой новой», «Новой» драмы, так называемой драмы.doc - как только критики их не называют... А может быть, и определения найти не могут, потому что, явление рождено не столько самой жизнью, сколько пришедшей из вне модой, удобством использования техники «verbatim»: тексты стали писать на основе откровенных дневников, документально записанных и «расчлененных» на реплики рассказов жертв, очевидцев катастроф и обыденного ужаса существования людей в разных субкультурах, за пределами социума - со всеми речевыми погрешностями самовыражения таких героев. Порой кажется, что ради этих «погрешностей» и пишется текст, что автор не столько потрясен бессмыслицей и ужасом события, сколько стремится шокировать способом его представления.

Но это направление, хотят или не хотят этого авторы, противостоит засилью коммерческих, большей частью «импортных» комедий на театре, уводящих от любой реальности. С выверенными сюжетными ходами, как говорили раньше, «хорошо сделанные» комедии положений давно делают свое дело: создают публику, которая идет в театр только для того, чтобы посмеяться над героями, попадающими в нелепые ситуации. Но между

${ }^{1}$ Монография была по его докторской диссертации. У меня защита докторской была впереди: в активе числилась кандидатская по творчеству Е. Шварца, несколько статей о драматургии М. Горького, В. Маяковского, С. Третьякова, А. Гельмана, шла работа над пьесами Г. Горина, В. Аксенова, В. Максимова, И. Бродского, др. Я серьезно думала об эпической драме как интереснейшем направлении в русской драматургии и очень обрадовалась появлению монографии «в тему»: на нее можно было теперь ссылаться! Во многом мы были единомышленниками, кое в чем расходились, хотя основания - Аристотель, тексты Брехта разного рода объединяли.

${ }^{2}$ Готовящийся к своему юбилею-75-летию А. С. Чирков в ужасе от того, что родившийся в разгар Второй мировой войны, он снова живет в условиях войны. 
эпатирующими экспериментами с их вниманием к страшной изнанке жизни и коммерческой комедией, за пределами внимания исследователей находится широкое поле поисков в других, в разных направлениях и вне направлений. Думается, на этом поле и растет необычное для русскоязычной драматургии нашего времени явление - пьесы исследуемого автора.

За последние полтора-два года он написал их более десяти ${ }^{3}$. Для меня это было полной неожиданностью. Состоявшийся, с именем ученый, организатор науки ${ }^{4}$, литературовед - и вдруг сам становится автором... Но, наверное, есть своя закономерность в том, что А. Чирков - исследователь эпической драмы и драматургии Б. Брехта, ученый, глубоко знающий западно-европейскую культуру, драму и театр от их истоков до современности, в сложных геополитических обстоятельствах заговорил на языке драмы, «помнящей», по М. Бахтину, весь свой прежний опыт.

Я, много размышлявшая об эпической драме ${ }^{5}$, заметила, что работали в этом направлении, как правило, те, кто писал и стихи. Они как-то по особенному и тексты реплик своим внутренним слухом слышали-«складывали»: Пушкин, Маяковский... и так до И. Бродского - автора пьесы Демократия! Самый значительный в исследованиях Чиркова - Брехт тоже начинал и продолжал стихами, включая их, в том числе, в качестве зонгов в пьесы. Вот и А. Чирков вписывается в этот ряд тем уже, что занимавшийся почти всю сознательную жизнь изучением драмы, он три года назад издал книжечку стихотворных притч и обратился к пьесам, явно используя ритмическую организацию текста, часто и рифмовку. Он не всегда акцентирует это визуально - специальным расположением строк-стихов на странице, выравниванием их одинаковым отступом слева, но емкость, отточенность, ударность стиха в его философских притчах способствует выражению мысли, выявлению тонкого, интеллектуального плана диалогов героев.

Брехт определял некоторые свои пьесы словом «парабола» ${ }^{6}$. Понимая параболу и притчу как синонимы, отметим, что это явление книжной культуры появилось в славянских литературах, видимо, с принятием и распространением христианства, с переводами Священного Писания, особенно Евангелия. Влияние проявилось, прежде всего, в широком использовании вымысла, условности. Притча в славянских литературах, замечает

\footnotetext{
${ }^{3}$ Семь из них он отобрал для книги: А. С. Чирков, Время и времена. Драмы-притчи, Житомир: «Видавець О.О. Эвенок» 2016.

${ }^{4}$ В его активе - организация работы кафедры, и не одной, аспирантуры, докторантуры, международных научных конференций, подготовка к изданию выпусков научных журналов, материалов конференций и т.д.

${ }^{5}$ В. Е. Головчинер, Эпическая драма в русской литературе ХХ века, Томск: Изд-во ТГПУ 2001, 2007.

${ }^{6}$ «Парабола (греч. - аллегорический рассказ, притча) - краткая иносказательная история поучительного содержания» - см.: А. П. Квятковский, Поэтический словарь, Москва: РГГУ 2013, с. 275.
} 
авторитетный ученый, «повествует о действительности в обобщенно-трансформированной форме», «фиксирует то, что, как кажется средневековому автору и читателю, было и будет существовать всегда, что неизменно или что случается постоянно» ${ }^{7}$ Высокая степень «поэтического вымысла» в притче, с одной стороны, освобождает автора от прописывания внешней фактурности, детализации изображения, с другой стороны, создает условия для концентрации смысла, для обобщения. Соотношение «действительного» и «вымышленного», выражение первого через второе, таким образом, существует в притче как коренное ее свойство. И еще, пожалуй, одно следует заметить в исследованиях о притче: она реализуется, главным образом, в повествовательных формах.

А опыт Брехта с его параболами, хорошо знакомый Чиркову, - это, прежде всего, опыт драматурга, автора эпических драм. Брехт в качестве важного фактора, делающего условным, остраняющим (термин В. Шкловского) действие его пьес, широко использовал сюжеты мировой культуры. Знаки (образы, мотивы, ситуации) известных культурных моделей фиксировали общечеловеческий опыт, привносили в новый текст когда-то кем-то уже сконцентрированный творческий потенциал, провоцировали читателя/ зрителя на сопоставление известного и новых его трансформаций у современного автора. Сравнивающий момент в восприятии текста определял его интеллектуальную природу.

А. Чирков, создающий свои пьесы в условно-метафорическом направлении эпической драмы ${ }^{8}$, обратился к выразительным возможностям притчи, которая изначально позволяет отказаться от какого бы то ни было реального основания. Не найдем мы у него прямых политических отсылок к современности, к ее узнаваемым героям. Они уступают место художественному исследованию поведения человека как такового, прочности содержания собственно человеческого в нем и результатов следования социальным искушениям.

Действуют в его притчах главным образом мужчины и женщины разных возрастов, обозначенные в ремарках самым общим образом: по гендерному признаку, по статусу в семье, в социуме. Это он, она; юноша, девушка; женщина, муж, жена; отец, сын; мать, сыновья; молодка, старуха. Или: разного рода учителя и ученики, первый, второй; философ, старейшины родов, жрец, монах, всадник. Предельно условно время и место действия, напоминающие то о ритуалах древних племен, то о культуре античности, то о средневековом театре на площади. Как будто в лабораторных условиях - в разной среде, при

${ }^{7}$ Д. С. Лихачев, Славянские литературы как система, [в:] Славянские литературы. IV Межндународный съезд славистов (Прага, авг. 1968). Доклады советской делегаиии, Москва: «Наука» 1968, с. 45.

${ }^{8}$ В. Е. Головчинер, К вопросу о статусе эпической драмы в системе драматического рода, «Драма и театр», вып. III, Тверь 2002, с. 7-22. 
разных температурах, на излом, на гибкость, способность извлекать уроки и отстаивать свои позиции проверяет их драматург, пытается понять, к чему, куда приведет общество тот или иной вариант поведения предводителя / вождя / правителя или того, кто претендует на эту роль; что ждет отдельных исполнителей его воли, массу зависимых от них, идущих за ними людей.

Творческое воображение А. Чиркова создает разные, совершенно неожиданные варианты испытания человеческого потенциала своих героев: созидательного или разрушительного - для себя, для других, для всех. Драматург пытается понять, что ведет человека в той или иной ситуации, к чему устремлен, какими средствами он действует, что побеждает в нем. Как скажется его сегодняшний поступок на судьбах его близких, его потомков. Что воспринимают ученики из слова учителя и насколько готовы следовать ему. Это проблемы вечные и всегда по-своему актуальные.

Для каждой пьесы А. Чирков находит свой оригинальный сюжетный ход, свою для каждого героя инициацию, точнее, - проверку его позиции, цены сделанного выбора. Есть драма-притча, действие которой связано с процессом определения героем линии своего поведения в экстремальной ситуации (в представлении Учителя и учеников в Проклятом отзывается далекое эхо споров об Иуде, о его самопожертвовании или предательстве во имя торжества Учителя и его веры). Есть пьеса, в которой ставится вопрос, чему учили Учителя и что восприняли, что сделали определяющим в своем жизненном поведении ученики: масштаб проблемы в Патине времен задается тем, что учителями оказываются великие философы античности - Платон, Сократ, Аристотель, а учениками - Герострат и Александр Македонский. Больше всего пьес, и это понятно, с вопросами о причинах трагических событий и их страшных последствиях для массы людей, с вопросами, кто правит, как, какими путями идет к власти, в чьих руках реально нити управления мировыми процессами (Вечные и смертныле, Когда проходят смуты времена, День силь, Играем севен).

По тому, как сделаны, мне были особенно интересны в книге драмы-притчи Патина времен и Когда проходят смуты времена, а по силе обобщения и остроте постановки проблем я бы выделила Играем севен.

Патина времен на фоне других притч в книге выделяется тем, что в ней действуют герои с именами, известными из древнегреческой культуры. В мировой драматургии пьес, в основу действия которых положена история подобного героя, множество. Но в том-то и дело, что автору Патины времен как драматургу эпического направления интересна не столько индивидуальная человеческая судьба кого бы то ни было из названных поименно персон, а группа равно важных лиц в соотношении их позиций и поведения. Вот он и собрал вместе тех, кто не мог в жизни встретиться по причине несовпадения отпущенного им судьбой времени: философов учителей человечества и в функциях «учеников»- уничтожившего храм Артемиды, седьмое чудо света Герострата и Александра Македонского, 
завоевательные походы которого принесли неисчислимые человеческие жертвы. Кто из персонажей этой притчи чего хотел и чего достиг? Эти вопросы решают для себя они сами. Но автор задает их и читателю.

На мою просьбу сообщить что-то об обстоятельствах, импульсах создания пьес Александр Семенович о Патине времен в письме от 10.02.2016 написал следующее:

Вначале написал Де істина?. Получилась очень громоздкая вещь с многочисленными сюжетными ходами. Была сильная привязка к историческому материалу, что меня не устроило. [...] Поэтому в том же 2015 году вновь обратился к этому сюжету и написал уже русскоязычный вариант, сохранив при этом название Где истина?. В этом варианте появился Диоген, как некое воплощение народного философа, противостоящего рафинированной философии великой античной троицы. Но преодолеть загруженность побочными линиями полностью не смог. И хотя по мысли второй вариант был стройнее и четче, но того, чего хотел, не достиг. В 2016 году опять вернулся к сюжету времен Александра Македонского. И это - принципиально новое произведение. Появились Пролог и Эпилог как своеобразные философские зачин и послесловие. Обострился конфликт Александра и Герострата, явным стало противостояние двух философских подходов и взглядов на предназначение и роль личности в истории. И тогда-то на первый план выступила проблема (вечная как мир), в чем же истинная суть человеческого бытия и людского жития?

Почему Александр Македонский и античные философы? Давно меня интересовал вопрос ответственности философов за практическое использование (внедрение) их идей в жизнь. А отсюда и роль личности, использующей философские концепции для реализации своих собственных представлений о мире, как мире изменяемом и меняющемся9 .

\section{А у пьесы Когда проходят смуты времена совсем другая история по-} явления.

Писал в декабре 2015 года. Среди моих притч есть одна - O слепой вере. Как много информации... Еще больше - дезинформации... Современные политтехнологи манипулируют сознанием людей, стремясь превратить человека, поверившего в нечто, в слепо верящего всему. Отсюда - многие беды и проблемы. Отсюда - недопонимание, перерастающее в непонимание. Более того - в нежелание понять другого. Об этом и размышлял в свое время в одной из своих притч.

Каждый верит тому, / Чему хочет верить. / Каждый верит тому, / Кому хочет верить. Но когда вера слепа, / Не заблудится ли верящий / Меж правдою и ложью? / И не поддержит ли он / Дело неправое, поверив в то, / Что оно - правое?

Правду невозможно познать, / Коли вера слепа.

Но был и внешний посыл. Причем - не один. Из ближней истории и из сегодняшнего дня. Начало XXI века - время распада-исчезновения одних государств и возникновения новых. Это - явление не локального, а глобального масштаба. А непосредственный

9 Здесь и далее цитируются письма А. Чиркова из архива автора статьи. Приношу искреннюю благодарность Александру Семеновичу за то, что позволил заглянуть на его «авторскую кухню». 
толчок - события на моей родине в последний год. Не познав и не поняв правду другого, невозможно познать истину. Правд много - истина одна.

Над этой информацией еще нужно размышлять.

Если Патина времен заинтересовала сразу количеством в одной пьесе знакомых из истории античности имен в перечне действующих лиц, остраняюших реальность, то пьеса Когда проходят смуты времена привлекла внимание предельным абстрагированием по линиям времени и пространства сразу, в первых авторских указаниях: «время действия: неве́домые времена», «место действия: земля трех родов и замок Магистра тайного ордена» и предельным освобождением номинаций героев от смысловых шлейфов. После естественных для притчи самых общих обозначений мать, отец, первый сын, др. в списке действующих лиц обнаруживались, в общем, возможные в притче, и все-таки озадачивающие Верба, Клен, Трава, Солнце, Река.

Но между перечнями двух групп действующих лиц (членов семьи, старейшин трех людских родов и Вербы, Клена, Травы, Солнца, Реки) пробелами с двух сторон выделена в центре группа лиц во главе с Магистром, как станет ясно в действии, враждебных тем и другим. В планах Магистра завладеть землями трех родов, подчинить их народ. Он напутствует Монаха:

А где ты видел народ? Я вижу только толпу... Скажу: наш орден для того и создан, чтоб народы превращать в толпу. А слухи, помни, куда как лучше справляются с этим, чем мечи... Так что - мечи бисер слухов перед иноверцами, мечи! Не надо, чтобы понимали. Главное, чтобы поверили. Такая вера иноверцев ослепит и лишит разума. Впрочем, это делает любая слепая вера. Так ослепи людей из трех родов, Монах. Грязной сплетней ослепи! Тогда слепые из толпы и пустят в ход свои мечи ${ }^{10}$.

Этот пример показывает, как отточена мысль драматурга, обличающего методы превращения народа в толпу не только по линии власти, беззастенчиво действующей с позиции силы, но и по линии большинства людей, которым внушенная вера заменяет разум, делает их слепыми, легко управляемыми. Обличение достигается тонкой игрой прямых и переносных значений слов, - игрой, обращенной к интеллекту воспринимающих текст. Остроумно и точно обнажает драматург политическую стратегию Магистра стяжением смыслов слов «мечи»- оружия (в множественном числе) и повелительного наклонения глагола «мечи» из идиоматического выражения «метать бисер перед свиньями». Обнаруживает в цепочке суждений персонажа противопоставление, взаимоисключение типов социального поведения людей разумных, понимающих и ослепленных верой. Магистру «не надо, чтобы понимали. Главное, чтобы поверили». Он по опыту знает, что «такая вера иноверцев ослепит и лишит разума. Впрочем, это делает

${ }^{10}$ А. С. Чирков, Время и времена ..., с. 135. 
любая слепая вера» [жирный шрифт мой - В. Г.]. Целенаправленно используемые сплетни, слухи, явный подкуп должны посеять вражду между братьями, старейшинами, в конце концов, приведут к войне, к уничтожению народов силами друг друга, чтобы возвысился до Божества Магистр.

Наверное, для понимания актуальности смысла этой притчи хватило бы и этого. Но автор ведет читателя к мысли, философски более емкой и масштабной. Горе матери, которой выпало на долю увидеть смерть сыновей от мечей друг друга в борьбе за власть, усилено сознанием того, что корень зла растет из прошлого ее семьи.

М а т ь. [...] За то, что предки мужа воевали / и земли у родов соседних отбирали, / страдать должны сыны? / Но погоди! Я - из того же рода. / И дед мой тоже воевал. / А значит, тоже убивал. / И бог наш это разрешал? / Иль поощрял... / Так значит, проклят род?

Клен. Правитель! И - народ! / У каждого из них - своя вина ${ }^{11}$.

Важность догадки матери о проклятье войны, передаваемом от поколения поколению, подчеркнута пульсирующим ритмом. Он не акцентирован автором визуально. Это я для демонстрации своей мысли отметила значком «/» стиховое, по сути, выражение эмоционального потрясения героини, энергию ее пробуждающейся мысли.

На развитие важной, по А. Чиркову, мысли работают в этой притче образы Вербы, Клена, Травы, Солнца, Реки. Только один персонаж пьесы - мать вступает с ними в контакт в самые тяжелые, самые отчаянные моменты переосмысления своей жизни и жизни своего рода. Ее мысль выходит за пределы личной судьбы, другим это не дано. Острота переживания потери мужа, невозможность справиться с раздором между сыновьями и сохранить единство трех родов выводят ее к контакту с силами природы. Она риторически обращается к Вербе («Верба! Верба! Как боль измучила меня!»), а во втором действии оказывается в прекрасном лесу, здоровается с ним и слышит ответные голоса. Много узнает от них, бывших когда-то людьми, уничтоженных воюющими. И дело не только в информации, которую мать узнает, а в том, что и она, и вместе с ней читатель получают ощущение единства и взаимосвязанности всего и всех в биосфере - давних поступков предков (а также наших сейчас) и судеб близких сегодня (и завтра), мира людского и природного. Ничто в нашем общем мире/времени не проходит бесследно.

Пьеса Играем севен написана из публикуемых в книге предпоследней, по сути, в одну ночь. 4 февраля 2016 я получила коротенькое письмо: «Сегодня поставил точку в саркастический драме (на одно действие) Играем севен... Сложилось. Теперь буду немного отдыхать. Скоро начало второго

${ }^{11}$ А. С. Чирков, Время и времена..., с. 152. 
семестра». В письме от 11.02.2016 дата создания уточнена, видимо, с учетом доработки.

Писал 7 февраля 2016. Думал значительно дольше. Трудно было найти надлежащую форму, чтобы события разных времен, стран и народов поместить в одно драматическое пространство. А начало, по мысли, - в притче моей:

Возжелав власти брата, / Сет убил Осириса.

Возжелав трон отца своего, / Крон оскопил Урана.

Возжелав славы друга, / Брут убил Цезаря.

Не потому ли и Каин убил Авеля, / что так во все времена

пишется история Земли?

Не возжелай!

Как и приведенная притча, Играем севен о природе власти и способах ее утверждения/удержания одним способом: какой бы век ни стоял на дворе, как бы ни назывался человек, народ, правитель - войной, подавляющей силой агрессии. Этот способ обозначен словом в сильной - конечной позиции первой же реплики пьесы: «война». Легко, как ракеткой в игре, подхватывает слово другой, третий персонаж, его саркатически обыгрывает автор за счет реплик «невпопад» Дамы и контекстом включенных в этот разговор строчек припева песенки, которая характеризуется на сайте Интернета как «блатная или дворовая» («Жена! Она от Бога нам дана. / С ней одной и радость, и покой»). Отметим и здесь, неакцентированную стиховую организацию текста в игровой функции.

Историк (Политику). Нет, что ни говори, но мир не может без войны.

Дама (Молодому слуге). Икорки больше положи.

Философ. Война от Бога нам дана.

Дама. Ах, эта красная икра.

Политик. И с ней одной нам радость и покой.

Дама. С икрой?

Политик. С войной! ${ }^{12}$

Текст пьесы Играем севен отмечен особой экономией и концентрацией выразительных средств. Это видно уже по приведенному началу пьесы, по поводу которого (и далее) следует отметить краткость реплик (а краткость, после А. П. Чехова, почитается за сестру таланта; в репликах драмы особенно), их ироническое обыгрывание контекстом и рифмой (дана / война / икра). Дама, как «блондинка» из современных анекдотов, своими репликами будет частенько остранять [жирный шрифт мой - В. Г.] и ставить под сомнение темы и смысл диалогов мужчин.

Экономия и концентрация выразительности средств заметна и в количестве действующих лиц. Их в обсуждаемой пьесе, в сравнении с другими,

${ }^{12}$ А. С. Чирков, Время и времена..., с. 190. 
необычайно мало. Здесь нет народных толп. Но появившиеся как Философ, Политик, Историк, Бизнесмен в «игре» оказываются в разных эпизодах Вождем, Великим князем, Императором («Элиты - из одной колоды карт. Они одной все масти и одинаково все рвутся к власти» $\left.{ }^{13}\right)$. И все озабочены проблемой управления, и все ее решение находят в войне: какая разница, какой.

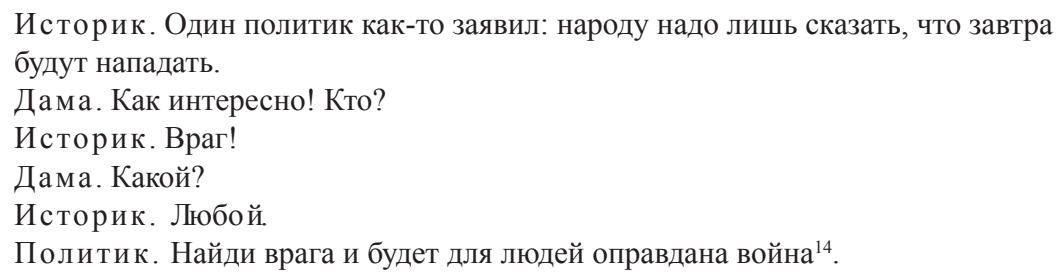

Выход из игры «севен» возвращает ее циничных участников к закускам - изыскам того фуршетного стола, у которого все начиналось. Кольцо, обнажая смысл, замкнулось: все высокие персоны, по сути, устремлены к потреблению, поеданию. Реальность не дает драматургу шансов для иного завершения. Но А. Чирков, чей почерк драматурга определялся изначально брехтовской школой, эстетически, уже за пределами действия дает последний энергичный зонг, предваряемый своеобразным «приветом» Брехту точной цитатой из финала его пьесы Добрый человек из Сезуана в реплике служанки (А. Чирков дает ее в переводе Б. Слуцкого).

Молодой слуга. Нет, это не финал. Таким ведь быть финал не может. Одна из служанок. Он должен, должен, должен быть хорошим! 15

22 февраля 2016 г. я написала эти строки, думая, что ими завершу свою статью о пьесах А. Чиркова. И вдруг с 26 на 27 марта (отмечу: Международный день театра) переписка наша снова активизировалась: возник замысел новой пьесы. Что-то предполагалось, уточнялось, отменялось и в несколько дней оформилось.

Замечательным мне показалось уже название новой пьесы-Сон ... в зимнюю ночь. Оно заставляло вспомнить Шекспира с его Сном в летнюю ночь. Но все в «зимнем» варианте пьесы контрастирует «летнему», возрожденческому, славящему любовь. Множество влюбленных героев самого разного возраста и социального положения, самых фантастических, только во сне возможных переплетений их историй Шекспира отступают у современного автора перед изображением героев, лишенных радостей, перед аскетизмом места, условий их жизни.

\footnotetext{
${ }_{13}^{13}$ А. С. Чирков, Время и времена..., с. 194.

${ }^{14}$ Там же, с. 192.

${ }^{15}$ Там же, с. 211.
} 
Историческое время не указано. Место действия - ограниченная каменными стенами келья монастыря. Героев, по сути, два: старый монах и молодой послушник, вся жизнь которого прошла в монастыре. Подкидыш, он не знает жизни за его пределами, как не знал родителей, детства. Старый монах день и ночь смиренно молится и к этому призывает послушника, а в нем бунтует молодость, он задает вопросы, на которые у отцовски любящего его монаха нет ответов. И молодой человек уходит от ранней утренней молитвы спать. В такой своеобразной форме выразились его сопротивление, отказ от безропотного подчинения заведенному в монастыре порядку, вызов безответности мира, его безучастности к судьбе молодого человека - мира представленного тем единственным человеком, которого он только и видит рядом, ничего не могущим не только изменить, но и прояснить.

Послушник засыпает и видит сон: раздвигаются стены монастыря, являются всем известные, жившие в давние и разные времена герои: дева-воительница, освободительница Орлеана и великий поэт, сочинивший поэму о походе крестоносцев, об освобождении Иерусалима. И Послушник задает свои вопросы им. А вокруг, все путая, всех очерняя, клубятся мрачные тени. Чего не бывает во сне... Ради него - сна, думается, и написана пьеса.

В творческом воображении автора пьесы актуализировалось его знание «большого времени культуры» (М. Бахтин). Он использовал выразительные возможности видения как формы, восходящей к сновидению, в разном объеме знакомой по центральной части Одиссеи Гомера, по сюжетной основе Божественной комедии Данте, религиозным текстам Средневековой Европы. Во времена формирования и активного функционирования жанра видения были рассказами об увиденном героями при посещении ими загробного мира, о мучающихся грешниках. Другая стратегия виденческого сюжета разрабатывалась в древнерусских версиях с опорой на Ветхий Завет: «некоему мужу» (визионеру) во сне или в другом, специфическом состоянии (после долгой молитвы, поста) из другого мира является - особое по своей значимости (сакральное) лицо, голос и сообщает текст, подает знак, воспринимаемые как пророческие. Но во всех случаях, ситуация контакта представителей разных миров оказывается для этого жанра основополагающей.

Вот и Послушник в пьесе ищет ответов на свои вопросы у героев ушедшей в прошлое «большой истории». Но истории их собственной жизни, как ни величественны для человечества результаты, трагичны. А клубящиеся тени хотят стереть в памяти человечества следы истинно великого, посеять сомнение в его возможности.

Зима в этой пьесе не столько время года, сколько метафора, выражающая состояние нашего мира, ощущение безысходности бытия и все-таки неустанный поиск ответов и желание жить. Ведь зима должна когда-нибудь кончиться...

Есть на канале «Культура» Российского телевидения передача Игра в бисер, ведущий которой после обсуждения очередного замечательного 
произведения с участием специалистов каждый раз призывает: «Читайте и перечитывайте классику!» Последнее слово не может быть употреблено по отношению к только появившейся летом 2016 г. книге пьес А. Чиркова, но опора этого автора на классические традиции в самом широком их спектре сообщает его пьесам «лица не общее выражение», делает их, безусловно, интересными для чтения, побуждающими к размышлению о дне сегодняшнем в контексте «большого времени культуры».

\section{References}

Chirkov, Aleksandr. Vremya i vremena. Dramy-pritchi. Zhitomir: «Vidavec O. O. Evenok», 2016.

Golovchiner, Valentina. Epicheskaya drama v russkoy literature XX veka. Tomsk: Izdatelstvo TGPU, 2007.

Golovchiner, Valentina. K voprosu o statuse epicheskoy dramy v sisteme dramaticheskogo goroda. In: Drama i teatr. III, ed. N. I. Ishchuk-Fadeeva, Tver': Tverskoy gosudarstvennyy universitet, 2002: 7-22.

Kvyatkovskiy, Aleksandr P. Poeticheskiy slovar'. Moskva: RGGU, 2013.

Likhachev, Dmitriy. C. Slavyanskie literatury kak sistema. In: Slavyanskie literatury. IV mezhdunarodnyy s"ezd slavistov (Praga, avg. 1968). Doklady sovetskoy delegatsii. Moskva: «Nauka», 1968. 